\title{
Blending of Sunflower Oil with Pomegranate Seed Oil from Blanched Seeds: Impact on Functionality, Oxidative Stability, and Antioxidant Properties
}

\author{
Tafadzwa Kaseke ${ }^{1,2}$, Umezuruike Linus Opara ${ }^{2, *(D)}$ and Olaniyi Amos Fawole $2,3, *$ (D) \\ 1 Department of Food Science, Faculty of AgriSciences, Stellenbosch University, Private Bag X1, \\ Stellenbosch 7602, South Africa; tafakaseqe@gmail.com \\ 2 Africa Institute for Postharvest Technology, South African Research Chair in Postharvest Technology, \\ Faculty of AgriSciences, Stellenbosch University, Private Bag X1, Stellenbosch 7602, South Africa \\ 3 Department of Botany and Plant Biotechnology, Faculty of Science, University of Johannesburg, P.O. Box 524, \\ Johannesburg 2006, South Africa \\ * Correspondence: opara@sun.ac.za (U.L.O.); olaniyi@sun.ac.za (O.A.F.)
}

Citation: Kaseke, T.; Opara, U.L.; Fawole, O.A. Blending of Sunflower Oil with Pomegranate Seed Oil from Blanched Seeds: Impact on Functionality, Oxidative Stability, and Antioxidant Properties. Processes 2021, 9, 635. https://doi.org/10.3390/ pr9040635

Academic Editor: Dariusz Dziki

Received: 8 March 2021

Accepted: 29 March 2021

Published: 5 April 2021

Publisher's Note: MDPI stays neutral with regard to jurisdictional claims in published maps and institutional affiliations.

Copyright: (c) 2021 by the authors. Licensee MDPI, Basel, Switzerland. This article is an open access article distributed under the terms and conditions of the Creative Commons Attribution (CC BY) license (https:/ / creativecommons.org/licenses/by/ $4.0 /)$.

\begin{abstract}
Seed oil blending is a novel approach that may enhance the oil antioxidant capacity. The study evaluated the effect of blending sunflower oil (SO) with pomegranate seed oil (BPSO) from blanched seeds $\left(95^{\circ} \mathrm{C} / 3 \mathrm{~min}\right.$ ) on oxidative stability and antioxidant properties of the oil blends. $\mathrm{SO}$ and pomegranate seed oil from unblanched seeds (PSO) were used as controls. Blending SO with BPSO and PSO was assessed in the following respective proportions: 90:10, 85:15, and 80:20 $(w / w)$ with respect to total phenolic content, total carotenoids content, tocopherols content, and fatty acid composition to establish the best blending ratio. An accelerated storage test was conducted using the best blending ratio (85:15) at $60 \pm 2{ }^{\circ} \mathrm{C}$ for 20 days. The evolution of peroxide value, $\rho$-anisidine value and, total oxidation value, together with the depletion of the oils' 2.2-azino-bis (3-ethylbenzothiazoline-6-sulfonic acid) (ABTS) and 2.2-diphenyl-1-picryl hydrazyl (DPPH) and radicals scavenging capacity were evaluated. Volatile oxidation compounds (VOCs) were assessed at the end of the accelerated storage test. Blended oils exhibited better oxidative stability than SO. Nevertheless, the oxidative stability of SO:PSO and SO:BPSO blends did not significantly vary. Additionally, blended oils showed a lower rate of DPPH and ABTS radical scavenging capacity depletion than SO, although this did not significantly vary between the oil blends. The concentration of VOCs was significantly higher in SO than blended oils. No significant difference in the content of VOCs was observed between SO:PSO and SO:BPSO blends. The findings of this study are valuable to the food industry, which is presently interested in nonconventional oils and functional foods to improve health and human nutrition.
\end{abstract}

Keywords: pomegranate seed; accelerated storage test; oil blends; tocopherols; total phenolic content; oxidative stability

\section{Introduction}

Lipid oxidation is one of the major causes of product quality deterioration in the food industry, particularly those high in polyunsaturated fatty acids (PUFA) such as edible seed oil due to their high sensitivity to oxidation [1]. In addition to imparting undesirable flavours and aromas, oxidation of fatty acids reduces food nutritional quality and may lead to the development of toxic compounds [2]. Therefore, lipid oxidation has detrimental effects both on food quality and human health. Synthetic antioxidants such as butylated hydroxyanisole, butylated hydroxyl toluene, and propylgallate have been primarily used to control lipid oxidation in edible seed oil. However, synthetic antioxidants may be associated with health risks such as skin allergies, gastrointestinal tract problems, and cancer [3]. In line with consumer demand for natural foods and risks associated with the 
use of synthetic antioxidants, alternative means to preserve edible oils and reduce the usage of synthetic antioxidants have been studied. The blending of two or more seed oil with different chemical properties has gained popularity due to its ability in altering the fatty acid profiles, improve natural antioxidants, oxidative properties, nutritional qualities, and industrial applications of the oils at relatively low cost [4]. Although seed oil blending is an old approach, the introduction of more new seed oils on the market has revived this approach and different types of specialty oils are being incorporated into conventional vegetable oils. Lipid oxidation may depend on the concentration of lipid-soluble antioxidant compounds and other factors, including fatty acid composition and processing. Due to refining, conventional seed oil significantly loses its functional and nutritional properties and oxidative stability.

Sunflower (Helianthus annuus L.) is one of the major oilseed crops. Sunflower oil is conventionally used as the most consumable edible oil in frying and, cooking; however, it has poor oxidative stability [2,5]. This is due to the degradation of antioxidant compounds such as tocopherols, carotenoids, and polyphenols during refining. Prior studies have demonstrated that blending sunflower oil with specialty oils improves its oxidative stability in addition to the nutritional properties. The studies of Ramadan and Wahdan [1] and Kiralan et al. [5] established that sunflower oil oxidative stability and nutritional qualities improved after blending with black cumin seed oil. Among the specialty oils, pomegranate seed oil (PSO) is a treasure of nutritional and health benefits due to high levels of antioxidant compounds such as punicic acid, tocopherols, carotenoids, and polyphenols. Due to these bioactive compounds, PSO possesses a variety of functional properties, including the prevention of lipid oxidation, obesity, diabetes, cancer, and improvement of the immune system [6].

As efforts by the food industry to provide quality and safer foods continue to grow, maximum recovery of the antioxidant compounds from the plant material has been prioritised. In this sense, treatment of the oil-bearing seeds has been reported to significantly enhance the recovery of antioxidant compounds and improve the oil oxidative stability [7]. Recently, blanching pomegranate seed has been shown to enhance the recovery of total phenolic compounds and improvement in oil antioxidant activity [8]. In spite of the numerous reports on the improvement of oil antioxidant compounds with seed pre-treatment [7], no studies have been carried out to further investigate the potential of the oil in enhancing the oil oxidative stability and functionality of conventional and less stable vegetable oils.

Therefore, the present study aimed to investigate the effect of blending sunflower oil with pomegranate seed oil from blanched seeds on the functionality, oxidative stability, and antioxidant capacity of sunflower oil. This study might assist in the development of healthy blended oils with improved oxidative stability and nutritional qualities.

\section{Materials and Methods}

\subsection{Plant Material}

Pomegranate fruits (cv. Herskawitz) used in the present were harvested at commercial maturity (total soluble solids: 14.02-16.61 Brix) from Blydeverwacht farm, Wellington $\left(33^{\circ} 48^{\prime} 0^{\prime \prime} \mathrm{S}, 19^{\circ} 53^{\prime} 0^{\prime \prime} \mathrm{E}\right)$ in Western Cape Province, South Africa, in March during the 2019 season. The fruits were stored in the Postharvest Technology Research Laboratory at Stellenbosch University at $7.5 \pm 0.5^{\circ} \mathrm{C}, 92 \pm 3 \%$ relative humidity $(\mathrm{RH})$ before processing to minimise deterioration in quality [7]. Seeds were manually separated from the peels, membranes, and juice before they were thoroughly cleaned with tap water. Sunflower seeds ( $3 \% w / w$ moisture content) were procured from a local supermarket (Stellenbosch, South Africa).

\subsection{Blanching Pretreatment and Sample Preparation}

Clean pomegranate seeds (PS) were blanched in a water bath (Scientific, Cape Town, South Africa) at $95 \pm 2{ }^{\circ} \mathrm{C}$ for $3 \mathrm{~min}$, as described in the study of Kaseke et al. [7]. The samples were immediately cooled in an ice-water bath and then dried in a hot oven at 
$55 \pm 2{ }^{\circ} \mathrm{C}$ to $2 \% w / w$ moisture content, to ensure minimum transfer of moisture into the extracted oil. Seed moisture content was measured using a moisture analyser $\left(100{ }^{\circ} \mathrm{C}\right)$ (KERN DBS60-3, Balingen, Germany).

\subsection{Oil Extraction}

Oil was extracted from the seeds according to the method described by Kaseke et al. [7]. For each sample, $60 \mathrm{~g}$ of uniformly ground seed powder ( $>1 \mathrm{~mm}$ particle size) was thoroughly mixed with $300 \mathrm{~mL}$ ethanol. The solvent was carefully chosen because it is less toxic, less hazardous, bio-renewable, and less expensive solvent, as compared to hexane [9]. The mixture was then sonicated $\left(700 \mathrm{~W}, 30 \pm 5{ }^{\circ} \mathrm{C}\right.$ for $\left.40 \mathrm{~min}\right)$ in an ultrasonic bath $(700 \mathrm{~W}$, $40 \mathrm{kHz}$, and $25 \mathrm{~L}$ capacity) (Scientific, Cape Town, South Africa). Oil was extracted in triplicates $(n=3)$. The solvent was recovered with a rotary evaporator (G3 Heidolph, Schwabach, Germany). A brownish precipitate, possibly formed from proteins and sugars after solvent removal, was separated from the oil before further processing or analyses.

\subsection{Neutralisation and Degumming of Sunflower Oil}

The sunflower oil (SO) was neutralised and degummed according to the method of Sanchez-Machado et al. [10]. Briefly, the crude SO was neutralised by adding the required amount of $3 \mathrm{~mol} / \mathrm{L} \mathrm{NaOH}$ at room temperature with continuous stirring. The mixture was then heated at $65{ }^{\circ} \mathrm{C}$ for $15 \mathrm{~min}$, after which it was cooled, and the oil separated from the aqueous solution and precipitates using a separation funnel. The neutralised SO was washed with distilled water $(20 \% w / w)$, and the water was separated from the oil. Degumming was carried out by heating the SO in a water bath at $70{ }^{\circ} \mathrm{C}$, adding boiling water $(20 \% v / v)$ and stirring the mixture for $10 \mathrm{~min}$. The degummed oil was cooled and then centrifuged at $4000 \mathrm{rpm}$ for $10 \mathrm{~min}$. Traces of moisture were removed by adding anhydrous sodium sulphate. To minimise oxidation, the filtered oil was stored in brown bottles at $4 \pm 2{ }^{\circ} \mathrm{C}$ until needed [2].

\subsection{Oil Blending}

Six oil blends were formulated by blending SO with pomegranate seed oil (BPSO) from blanched seeds and pomegranate seed oil from unblanched seeds (PSO) (control samples), in proportions of 90:10, 85:15, and 80:20 (w/w). The oils were thoroughly mixed at room temperature $\left(25-27^{\circ} \mathrm{C}\right)$ to form uniform blends.

\subsection{Characterisation of Sunflower Oil and Oil Blends}

\subsubsection{Total Phenolic Content and Total Carotenoids Content Determination}

The total phenolic contents were determined using the Folin Ciocalteu reagent [11]. The standard curve was linear between 0.0 and $20 \mathrm{mg} / \mathrm{mL}$ ), and the results were expressed as milligram gallic acid equivalent per $\mathrm{g}$ PSO (mg GAE/g PSO). Total carotenoids content was evaluated according to Ranjith et al. [12]. $\beta$-carotene $(0.5-100 \mu \mathrm{g} / \mathrm{mL})$ was used as the standard and results were reported as $\mathrm{mg} \beta$-carotene $/ \mathrm{g}$ of oil.

\subsubsection{Tocopherols Determination}

Oil $(150 \mathrm{mg})$ in glass vials $(15 \mathrm{~mL})$ was mixed with a saponification reagent $(2.5 \mathrm{~mL})$ prepared from absolute ethanol, $33 \%(w / v)$ potassium hydroxide, and $20 \%(w / v)$ ascorbic acid [13]. The mixture was vortexed and then saponified in an oven at $60{ }^{\circ} \mathrm{C}$ for $1 \mathrm{~h}$. The saponified samples were cooled on ice for $10 \mathrm{~min}$, after which $5 \mathrm{~mL}$ of distilled water and $2 \mathrm{~mL}$ of chloroform were added and the mixture vortexed. The samples were centrifuged at $3000 \mathrm{rpm}$ for $4 \mathrm{~min}$. The chloroform extracts $(500 \mu \mathrm{L})$ were transferred into $2 \mathrm{~mL}$ glass vials and concentrated with a gentle stream of nitrogen to $\pm 200 \mu \mathrm{L}$. To $100 \mu \mathrm{L}$ of the chloroform extracts, pyridine $(100 \mu \mathrm{L})$ and N,O-Bis (trimethylsilyl) trifluoroacetamide $(30 \mu \mathrm{L})$ were added, and the mixture was vortexed and then derivatised in an oven at $100{ }^{\circ} \mathrm{C}$ for $1 \mathrm{~h}$. The silylated tocopherols fractions were analysed using gas chromatography coupled with mass spectrometry (Thermo Scientific Co. Ltd., Milan, Italy). The initial injected 
temperature was $100{ }^{\circ} \mathrm{C}$ and held for $2 \mathrm{~min}$ and then heated to $250{ }^{\circ} \mathrm{C}$ at the speed of $7^{\circ} \mathrm{C} / \mathrm{min}$ and maintained for $2 \mathrm{~min}$. The split ratio and injection volumes were $5: 1$ and $1.0 \mu \mathrm{L}$, respectively. Helium was used as the gas carrier with a flow rate of $1 \mathrm{~mL} / \mathrm{min}$. The mass spectrometer was operated under electron impact mode at ionisation energy of $70 \mathrm{eV}$, scanning from 40 to $650 \mathrm{~m} / \mathrm{z}$. A standard prepared from a mixture of $\alpha, \beta, \gamma$, and $\delta$-tocopherols was used to identify peaks. The final results were reported as $\mu \mathrm{g} / \mathrm{g}$ of oil.

\subsubsection{Fatty Acid Composition Determination}

The gas chromatography-mass spectrometry (GC-MS) method was employed [14]. Briefly, oil $(0.1 \mathrm{~g})$ was mixed with hexane $(2.0 \mathrm{~mL})$, heptadecanoic acid $(50 \mu \mathrm{L}, 1000 \mathrm{ppm}$, internal standard), and $\mathrm{H}_{2} \mathrm{SO}_{4}$ in methanol $(1.0 \mathrm{~mL}$ of $20 \% \mathrm{v} / \mathrm{v})$, vortexed and incubated for $1 \mathrm{~h}$ in an oven set at $80{ }^{\circ} \mathrm{C}$. To the cooled mixture, saturated $\mathrm{NaCl}(3 \mathrm{~mL})$ was added, after which the samples were vortexed and centrifuged (Centrifuge 5810R, Eppendorf, Germany). The gas chromatograph (6890 N, Agilent Technologies network) with a mass selective detector (Agilent Technologies inert XL EI/CI) (5975B, Agilent Technologies Inc., Palo Alto, CA, USA) was used to analyse the supernatant (hexane extracts). The analytical GC conditions were as follows: oven temperature $100^{\circ} \mathrm{C} / \mathrm{min}, 180{ }^{\circ} \mathrm{C}$ at $25^{\circ} \mathrm{C} / \mathrm{min}$ for $3 \mathrm{~min}, 200{ }^{\circ} \mathrm{C}$ at $4{ }^{\circ} \mathrm{C} / \mathrm{min}$ for $5 \mathrm{~min}, 280{ }^{\circ} \mathrm{C}$ at $8{ }^{\circ} \mathrm{C} / \mathrm{min}$, and $310{ }^{\circ} \mathrm{C}$ at $10{ }^{\circ} \mathrm{C} / \mathrm{min}$ for $5 \mathrm{~min}$; injection volume $1 \mu \mathrm{L}$, injector split ratio $1: 10$; flow rate $0.017 \mathrm{~mL} / \mathrm{s}$; helium as carrier gas injector. The National Institute of Standards and Technology (NIST) library was used to identify the fatty acid profiles. The relative content (\%) of each fatty acid was calculated by dividing the peak area of each fatty acid by the total peak area of all the fatty acids identified.

\subsubsection{Calculated Oxidisability (COX) Value}

The calculated oxidisability (COX) value of the oil samples was calculated by applying the formula proposed by Fatemi and Hammond [15].

$$
\mathrm{COX} \text { value }=\frac{\mathrm{C} 18: 1 \%+10.3 \times \mathrm{C} 18: 2 \%+21.6 \times \mathrm{C} 18: 3 \%}{100} .
$$

\subsection{Accelerated Oxidation Experiments of SO and Oil Blends}

The accelerated stability test (Schaal oven test) was performed to evaluate the oxidative stability of SO and oil blended at an 85:15 $(w / w)$ ratio. The blending ratio was selected based on the oils characterisation results, which demonstrated that blending SO and BPSO at this ratio significantly improved total phenolic compounds and $\alpha$-tocopherols when compared with SO:PSO blend, and further increasing PSO in the oil blends $(80: 20(w / w))$ did not significantly improve the total phenolic compounds and tocopherols. SO and oil blends $(10 \mathrm{~mL})$ were transferred to transparent glass bottles $(15 \mathrm{~mL})$ without covers. The oxidation reaction was accelerated in a forced-draft air oven at $60 \pm 2{ }^{\circ} \mathrm{C}$ in darkness for 20 days. Samples of each treatment were removed on a five-day interval for lipid oxidation and radical scavenging capacity evaluation. Each treatment was prepared in triplicate $(n=3)$.

\subsection{Monitoring Oil Oxidative Stability and Radical Scavenging Capacity}

2.8.1. Peroxide Value, $\rho$-Anisidine Value, and Total Oxidation Value

The progression of oil oxidative deterioration was monitored using peroxide value (PV), $\rho$-anisidine value (AV), and the total oxidation value (TOTOX). The modified ferrous oxidation-xylenol orange (FOX) method [16] was employed to determine PV. AV was determined according to the American Oil Chemists' Society (AOCS) method [17]. PV and AV were used to calculate the TOTOX value (Equation (2)).

$$
\mathrm{TOTOX}=2 \mathrm{PV}+\mathrm{AV}
$$




\subsubsection{DPPH Radical Scavenging Capacity}

The 2, 2-diphenyl-1-picryl hydrazyl (DPPH) radical scavenging capacities of $\mathrm{SO}$ and oil blends were determined according to the method of Siano et al. [18]. In brief, $2.5 \mathrm{~mL}$ of DPPH $(0.004 \%(w / v))$ solution in methanol $(80 \%(v / v))$ was added to $200 \mu \mathrm{L}$ aliquot of oil methanol extracts, after which the samples were vortexed and incubated for $60 \mathrm{~min}$ in darkness. The absorbance was measured at $517 \mathrm{~nm}$ using a UV spectrophotometer (Spectrum Instruments, United Scientific, Cape Town, South Africa). Trolox standard (5-100 $\mathrm{mM}$ ) was used to plot the calibration curve and the results were reported as $\mathrm{mmol}$ Trolox/g of oil.

\subsubsection{ABTS Radical Scavenging Capacity}

Briefly, equal volumes of potassium per-sulphate solution $(2.6 \mathrm{mM})$ and 2.2 -azino-bis (3-ethylbenzothiazoline-6-sulphonic acid) (ABTS) solution (7.4 mM) and were mixed and the solution kept in the dark for 12-16 h [19]. An aliquot of $1.5 \mathrm{~mL}$ from the stock solution was added to $40 \mathrm{~mL}$ of $80 \%(v / v)$ methanol, and the absorbance of the solution at $750 \mathrm{~nm}$ was adjusted to $0.7 \pm 0.02$ with $80 \%(v / v)$ methanol. Aliquots of $300 \mu \mathrm{L}$ methanol oil extracts were mixed with $300 \mu \mathrm{L}$ freshly prepared ABTS solution. After incubating the samples in the dark for $10 \mathrm{~min}$, a microplate reader (Thermo Fisher Scientific, Shanghai, China) was used to measure the absorbance at $750 \mathrm{~nm}$. A calibration curve was prepared using Trolox (5-100 $\mathrm{mM}$ ) as the standard solution. The results were expressed as mmol Trolox/g of oil.

\subsection{Determination of Reaction Order and Reaction Rate Constants}

The PV, AV, TOTOX evolution, DPPH, and ABTS radical scavenging capacity depletion reaction order and rate constants $\left(\mathrm{k}, \mathrm{day}^{-1}\right)$ during the accelerated storage period were determined by fitting the data into zero- and first-order kinetic models using linear regression based on the following equations:

Zero-order kinetic model:

$$
\mathrm{C}_{\mathrm{A} 0}-\mathrm{C}_{\mathrm{A}}=\mathrm{kt}
$$

First-order kinetic model:

$$
\ln \frac{\mathrm{C}_{\mathrm{A} 0}}{\mathrm{C}_{\mathrm{A}}}=\mathrm{kt}
$$

where $\mathrm{C}_{\mathrm{A} 0}$ and $\mathrm{C}_{\mathrm{A}}$ are the concentrations of oxidation indices $(\mathrm{PV}, \mathrm{AV}$, and TOTOX) and radical scavenging capacity (DPPH and ABTS), $\mathrm{k}$ is the reaction rate constant $\left(\right.$ day $^{-1}$ ), and $t$ is the time (days). The model with a higher correlation coefficient $\left(R^{2}\right)$ was selected as the best fitting reaction order.

\subsection{Volatile Oxidation Compounds Analysis}

The headspace-solid phase microextraction (HS-SPME) coupled to gas chromatography mass spectrometry (GC-MS) was used to analyse the volatile oxidation compounds (VOCs) [20]. A total of 200 microlitres $(200 \mu \mathrm{L})$ of oil samples were inserted in $20 \mathrm{~mL}$ SPME vials and $1 \mu \mathrm{L}$ was injected onto the SPME-GC-MS system. The volatiles were separated on a ZBWaxPlus ( $30 \mathrm{~m}, 0.25 \mathrm{~mm}$ ID, $0.25 \mu \mathrm{m}$ film thickness) capillary column in a gas chromatograph $(6890 \mathrm{~N}$, Agilent Technologies network (Palo Alto, CA, USA)) coupled to an Agilent Technologies inert XL EI/CI mass selective detector (MSD) (5975B, Agilent Technologies Inc., Palo Alto, CA, USA) and a CTC Analytics PAL autosampler. The carrier gas was helium $(1 \mathrm{~mL} / \mathrm{min})$. The samples were injected in splitless mode at $250{ }^{\circ} \mathrm{C}$. The GC analytical conditions were follows: oven temperature $35^{\circ} \mathrm{C}$ for $5 \mathrm{~min}$, then ramped at $5{ }^{\circ} \mathrm{C} / \mathrm{min}$ until $50^{\circ} \mathrm{C}$ and held for $3 \mathrm{~min}$, and ramped again at a rate of $5^{\circ} \mathrm{C} / \mathrm{min}$ until $120^{\circ} \mathrm{C}$ and held for $3 \mathrm{~min}$, and finally ramped up to $240{ }^{\circ} \mathrm{C}$ at a rate of $10^{\circ} \mathrm{C} / \mathrm{min}$ for $3 \mathrm{~min}$. The MSD was operated in a full scan mode and the source and quad temperatures were maintained at $230^{\circ} \mathrm{C}$ and $150^{\circ} \mathrm{C}$, respectively. The transfer line temperature was maintained at $250{ }^{\circ} \mathrm{C}$. The mass spectrometer was operated under electron impact (EI) mode at ionisation energy of $70 \mathrm{eV}$, scanning from 25 to $650 \mathrm{~m} / \mathrm{z}$. The mass spectral data of 
samples were used to identify the compounds using the standard NIST and Wiley Library and by comparing the retention times. To calculate the relative content (\%) of each VOC, the peak area of each component was divided by the total peak area of all the VOCs identified.

\subsection{Statistical Analysis}

One-way analysis of variance (ANOVA) was carried out using Statistica software (Statistical v13, TIBC, Palo Alto, CA, USA). The mean values were separated according to Duncan's multiple range test and results are presented as mean $\pm S D$ (standard deviation) was used for graphical presentations. Graphical presentations and correlations were conducted using Microsoft Excel software (XLSTAT 2019.4.1.63305, Addinsoft, New York, NY, USA) and Microsoft Excel (Version: 16.0.13029.20344, Microsoft Cooperation, Washington, DC, USA), respectively.

\section{Results and Discussion}

\subsection{Fatty Acid Composition of SO and Oil Blends}

Fatty acid composition is valuable in determining the nutritional, functional, and oxidative stability properties of edible oils. The fatty acid composition of SO, PSO, BPSO, and oil blends is presented in Table 1 . Although the fatty acid content of SO significantly varied from the blended oils, no significant differences in the fatty acid composition were observed among the blended oils. This finding suggests similarities in the fatty acid composition of pomegranate seed oil from unblanched and blanched pomegranate seed [7]. The primary fatty acids were linoleic, cis-oleic, palmitic, and stearic acids, which accounted for $64.46 \%, 24.13 \%, 6.69 \%, 4.29 \%$ in SO; $15.95 \%, 10.17 \%, 8.10 \%, 2.32 \%$ in PSO and $9.93 \%, 7.45 \%, 5.67 \%$ and $1.95 \%$ in BPSO, respectively. The profile of fatty acids in SO was comparable to the findings of Latif and Anwar [21] from enzyme-extracted oil. SO was richer in linoleic acid, cis-oleic, and steric acid than PSO and BPSO. However, PSO and BPSO were characterised by high levels of PUFA, which ranged between 75.18 and 78.59\%, and this may be attributed to punicic acid, an 18:3 cis-9, trans- 11 , cis-13 fatty acid unique to pomegranate seed oil. In line with this, a slight increase in the blended oils calculated oxidisability (Cox) value was also observed (Table 1). Blending SO with both PSO and BPSO significantly increased the primary saturated fatty acids such as palmitic and stearic acid. It should be noted that, although there was a significant increase in palmitic acid and stearic acid after blending, the levels remained low. Literature has also reported similar findings. For instance, Ramadan et al. [1] blended corn oil with black cumin seed oil $(80: 20, w / w)$ and reported that palmitic acid and stearic acid increased from 9.46-10.1\% and $2.90-2.95 \%$, respectively. Nevertheless, the amount of each fatty acid in the oils after blending could have been affected by the changes that happened to other fatty acids, matrices of the blended oils, and oil blending efficiency. Depending on the type of seed oil, blending may enhance the saturated fatty acids. In a related study, Bhatnagar et al. [22] also observed a marked increase in saturated fatty acids after blending coconut oil with various oils, including sunflower, safflower, palm, and sesame seed oil. Even though saturated fatty acids are associated with adverse health effects, stearic acid has unique properties. Saturated fatty acid has been reported to decrease low-density lipoprotein (LDL) cholesterol, cancer, and atherosclerosis risk [23]. Blending SO with PSO and BPSO significantly increased stearic acid content between 2 to $3 \%$. The levels of monosaturated fatty acids (MUFA) significantly improved between 1 and $2 \%$, whilst the concentration of polyunsaturated fatty acids (PUFA) insignificantly changed after oil blending. The observation that MUFA significantly increased after blending suggests improved oxidative stability of the oils. In a previous study, Ramadan and Wahdan [1] also reported significant improvement in MUFA after blending corn oil and black cumin seed oil and attributed the enhancement to increased levels of oleic acid. The increase in unsaturated to saturated fatty acids (UFA/SFA) index after oil blending suggests that blending SO with PSO may enhance the SO nutritional quality. 
Table 1. Fatty acid composition of sunflower oil, pomegranate seed oil, and oil blends.

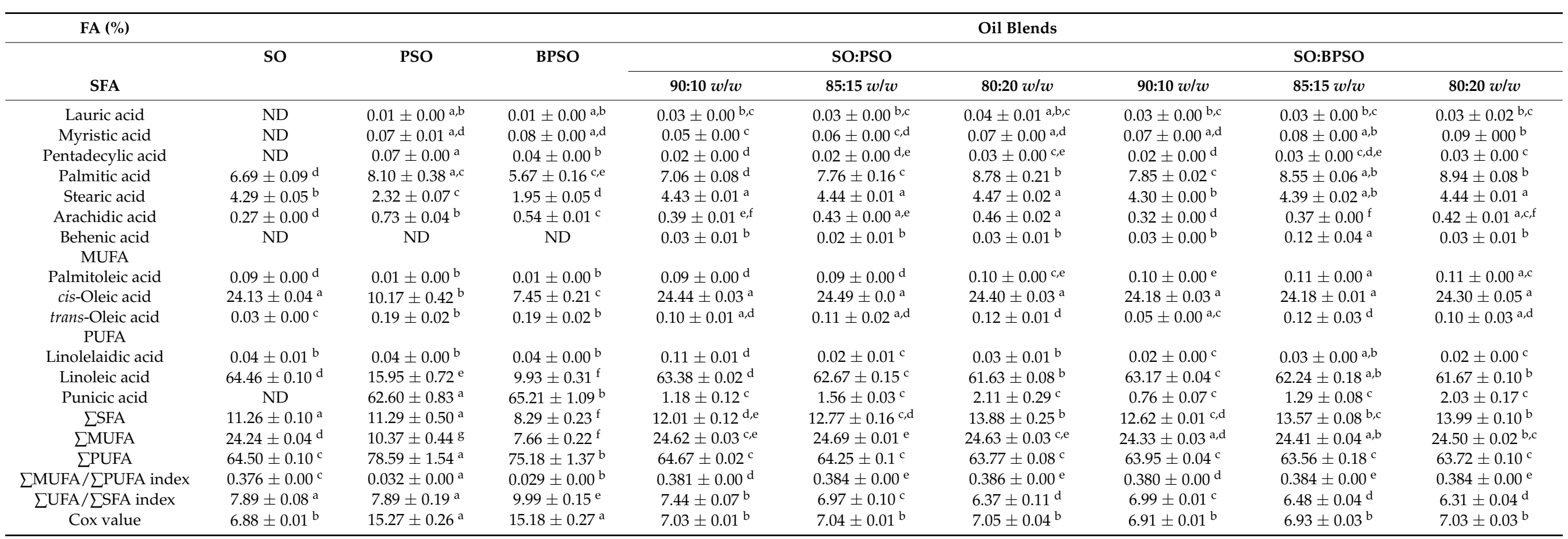

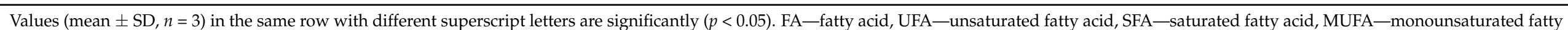

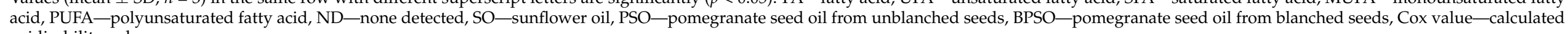
oxidisability value. 


\subsection{Total Phenolic Content, Total Carotenoids Content, and Tocopherol Composition of SO and Oil Blends}

Total phenolic content (TPC) is an important quality factor that determines the antioxidant potency and oxidative stability of seed oil. Table 2 shows that the TPC of PSO and BPSO was 10- and 11-fold higher than that of SO. Blending the oils, significantly improved the TPC between 0.37 and $0.49 \mathrm{mg} \mathrm{GAE} / \mathrm{g}$, suggesting improved oxidative stability of the oils. Comparable observations were reported in the study of Nadeem et al. [24] after blending butter oil and moringa seed oil. The authors further reported a $70 \%$ increase in butter oil oxidative stability (induction period) after incorporating moringa seed oil. Although BPSO oil blends exhibited higher TPC than PSO blends, the levels were not significantly different. Dietary carotenoids have been associated with the prevention of cancer and eye diseases. Partly, the health benefits of carotenoids are believed to be linked to their role as antioxidants [3]. The TCC in SO, PSO and BPSO were $0.01,0.19$, and $0.17 \mathrm{mg}$ $\beta$-carotene $/ g$, respectively (Table 1 ). After blending SO with PSO and BPSO, the TCC significantly increased by 50 to $80 \%$. SO:BPSO (80:20) blend showed the highest level of TCC among the oil blends.

Tocopherols, the major lipid-soluble antioxidants have been implicated in the prevention of cardiovascular diseases and certain types of cancers. Moreover, tocopherols play an important role in trapping the hydroperoxides intermediates and stopping the autoxidation chain reaction [3]. The antioxidant activity of tocopherols is attributed to their ability to donate their phenolic hydrogen to lipid-free radicals and hinder the lipid peroxidation process [25]. In the current study, $\alpha$ and $\delta$-tocopherols were identified in SO, PSO, BPSO, and oil blends (Table 2). The levels of $\alpha$ and $\delta$-tocopherols in this study were lower, compared to literature, indicating losses during the GC-MS analysis. Lower levels of tocopherols in both SO ( $\delta$-tocopherols: $12.4 \mu \mathrm{g} / \mathrm{g}$ ) and SO:PSO blend ( $\delta$-tocopherols: $13.2 \mu \mathrm{g} / \mathrm{g}$ ) have been reported in similar studies [26]. The extraction efficiency of tocopherols may depend on the size, polarity of the tocopherols, and whether they exist as free or complexed molecules in the seed matrix [3]. The $\alpha$-tocopherol which is the most efficient on scavenging peroxyl radicals in homogenous tocopherols was significantly higher in PSO $(55.45 \mu \mathrm{g} / \mathrm{g})$ and BPSO $(63.84 \mu \mathrm{g} / \mathrm{g})$ when compared to SO $(26.28 \mu \mathrm{g} / \mathrm{g})$.

Similarly, PSO and BPSO showed higher levels of $\delta$-tocopherol than SO (Table 2). The BPSO and SO blended at 85:15 and 80:20 ratio, significantly improved in $\alpha$-tocopherol by 2 and 5-fold, respectively. Blending SO and PSO did not significantly enhance $\alpha$-tocopherol. Previously, Ramadan and Wahdan [1] blended corn and black cumin seed oil and observed a decrease in $\alpha, \gamma$, and total tocopherol but still observed significant improvement in oxidative stability of the blended oils. In the seed matrix, tocopherols may exist freely or bound to other compounds, which may influence their extractability. Significantly higher improvement in $\delta$-tocopherol was exhibited by SO:PSO (85:15) (51\%) and SO:BPSO $(80: 20)(41 \%)$ blends, respectively. The lower levels of tocopherols in SO could be due to losses during degumming and neutralisation, justifying the motive to blend it with pomegranate seed oil from the blanched seed. It can be stated that the higher levels of tocopherols detected in PSO and BPSO could contribute to the stability of the oil blends towards lipid oxidation. 
Table 2. Total phenolic content (TPC), total carotenoids content (TCC), and tocopherols of sunflower oil, pomegranate seed oil, and oil blends.

\begin{tabular}{|c|c|c|c|c|c|c|c|c|c|}
\hline \multirow{3}{*}{ Parameter } & \multirow{3}{*}{ so } & \multirow{3}{*}{ PSO } & \multicolumn{7}{|c|}{ Oil Blends } \\
\hline & & & BSPO & \multicolumn{3}{|c|}{ SO:PSO } & \multicolumn{3}{|c|}{ SO:BPSO } \\
\hline & & & & $90: 10 w / w$ & $85: 15 w / w$ & $80: 20 w / w$ & $90: 10 w / w$ & $85: 15 w / w$ & $80: 20 w / w$ \\
\hline TCC (mg $\beta$-carotene $/ \mathrm{g}$ ) & $0.01 \pm 0.00^{\mathrm{d}}$ & $0.19 \pm 0.01^{b}$ & $0.17 \pm 0.01^{c}$ & $0.02 \pm 0.00^{\mathrm{d}, \mathrm{e}}$ & $0.03 \pm 0.00^{\mathrm{e}, \mathrm{f}}$ & $0.04 \pm 0.00^{\mathrm{a}, \mathrm{f}}$ & $0.02 \pm 0.00^{\mathrm{d}, \mathrm{e}}$ & $0.04 \pm 0.00^{\mathrm{a}, \mathrm{f}}$ & $0.05 \pm 0.00^{\mathrm{a}}$ \\
\hline TPC (mg GAE/g) & $0.35 \pm 0.01^{c}$ & $3.45 \pm 0.35^{\mathrm{a}}$ & $3.89 \pm 0.20^{b}$ & $0.69 \pm 0.03^{c, d}$ & $0.73 \pm 0.01^{c, d}$ & $0.82 \pm 0.07 \mathrm{~d}$ & $0.66 \pm 0.03^{c, d}$ & $0.84 \pm 0.01 \mathrm{~d}$ & $0.83 \pm 0.01 \mathrm{~d}$ \\
\hline \multicolumn{10}{|l|}{ Tocopherols $(\mu \mathrm{g} / \mathrm{g})$} \\
\hline$\alpha$-tocopherol & $26.28 \pm 5.19^{c}$ & $55.45 \pm 8.23^{b}$ & $63.84 \pm 2.36^{\mathrm{b}}$ & $31.98 \pm 3.11^{c}$ & $31.07 \pm 1.78$ & $29.87 \pm 4.27^{c}$ & $24.87 \pm 4.50^{c}$ & $54.40 \pm 11.52^{b}$ & $59.68 \pm 3.11^{b}$ \\
\hline$\delta$-tocopherol & $13.28 \pm 0.32^{\mathrm{d}}$ & $36.31 \pm 2.63^{a}$ & $16.78 \pm 1.62^{b, c, d}$ & $14.79 \pm 0.53^{c, d}$ & $20.07 \pm 1.94^{b}$ & $16.65 \pm 0.74^{b, c, d}$ & $15.05 \pm 061^{b, c, d}$ & $18.09 \pm 1.73^{b, c, d}$ & $18.70 \pm 2.04^{b, c}$ \\
\hline
\end{tabular}

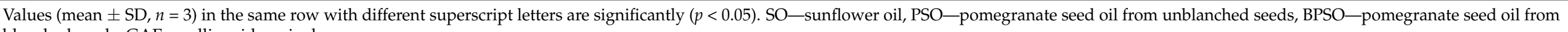
blanched seeds, GAE—gallic acid equivalence. 


\subsection{Oxidative Indices Changes during Accelerated Storage}

\subsubsection{Peroxide Value}

Peroxide value is an important index for the evaluation of peroxides and hydroperoxides, predominant during the initial stages of lipid oxidation. The higher the seed oil oxidative stability is, the slower the rate of hydroperoxides generation and PV increase [27]. Figure 1a shows that blending SO with PSO and BPSO decreased the rate of hydroperoxides formation during the accelerated storage period. Despite the initially lower PV in SO:BPSO blend (1.48 meqO ${ }_{2} / \mathrm{kg}$ oil), compared to $\mathrm{SO}\left(1.92 \mathrm{meqO}_{2} / \mathrm{kg}\right.$ oil $)$ and SO:PSO blend ( $2.00 \mathrm{meqO}_{2} / \mathrm{kg}$ oil), the oils showed similar oxidative deterioration patterns after five days of accelerated storage. This can be explained by the presence of a relatively higher concentration of antioxidants such as phenols and carotenoids. Furthermore, the synergistic effect of these antioxidant compounds could have prevented the initiation of hydroperoxides generation or improved the antioxidants scavenging of the peroxyl radicals, thereby inhibiting the propagation of radical chain reactions, hence the low rate in PV increase [28].

After 10 days of accelerated storage, the PV in SO:PSO and SO:BPSO blends increased at a slower rate than that of SO. This could be explained by relatively higher TPC, TCC, and tocopherols in addition to the increased ratio of MUFA to PUFA in the oil blends. It is imperative to mention that the oxidative stability of MUFAs is greater than PUFAs, which are the major substrate for oil oxidation. In respect of PV from SO:PSO and SO:BPSO blends, no significant differences were observed, indicating that the oxidative stability of the oils was similar, despite the $\alpha$-tocopherols being significantly higher in SO:BPSO blend. In addition to synergism, antioxidants may also show antagonism interactions. Choe and Min [29] reported that phenolic compounds such as caffeic acid are antagonistic to the antioxidant function mechanism of $\alpha$-tocopherols. Notably, after 10 days of accelerated storage, the PVs of all the oil samples were above the rancidity limit of $15 \mathrm{meqO}_{2} / \mathrm{kg}$ oil according to Codex Alimentarius Commission [30]. In another study, various blends of palm and macadamia oils under accelerated storage conditions at $60^{\circ} \mathrm{C}$ reached their shelf life within 15 days of storage for PV [31]. In that study, the blended oils were characterised by higher levels of MUFAs and SFAs, compared to PUFAs.

As shown in Figure 2, the reaction rate constants $\left(k\right.$, day $\left.^{-1}\right)$ for PV in SO:PSO $\left(0.155 \mathrm{meqO}_{2}{ }^{(\mathrm{n}-1)} \cdot\right.$ day $\left.^{-1}\right)$ and SO:BPSO $\left(0.152 \mathrm{meqO}_{2}{ }^{(\mathrm{n}-1)} \cdot\right.$ day $\left.^{-1}\right)$ blends did not significantly $(p>0.05)$ vary during the entire storage period. The levels of PV in SO, PSO, and BPSO were $50.15,46.71$, and $46.78 \mathrm{meqO}_{2} / \mathrm{kg}$ oil, respectively, at the end of the accelerated storage experiment. The high PV in blended oils at the end of the storage experiment, suggests that the presence of punicic acid (18: 3 fatty acid) in oil blends could have increased the oxidisability of the oils (Table 1). According to Fatemi and Hammond [15], the oxidation of 18:3 fatty acids is 2- and 22-fold higher than that of 18: 2 and 18:1 fatty acid, respectively. In a related study, PV ranging from 117.78-346.16 was reported from sunflower oil blended with black cumin seed oil after 16 days of accelerated storage at $60{ }^{\circ} \mathrm{C}$ [5]. Similar to our findings, the blended oils had high levels of PUFAs. 


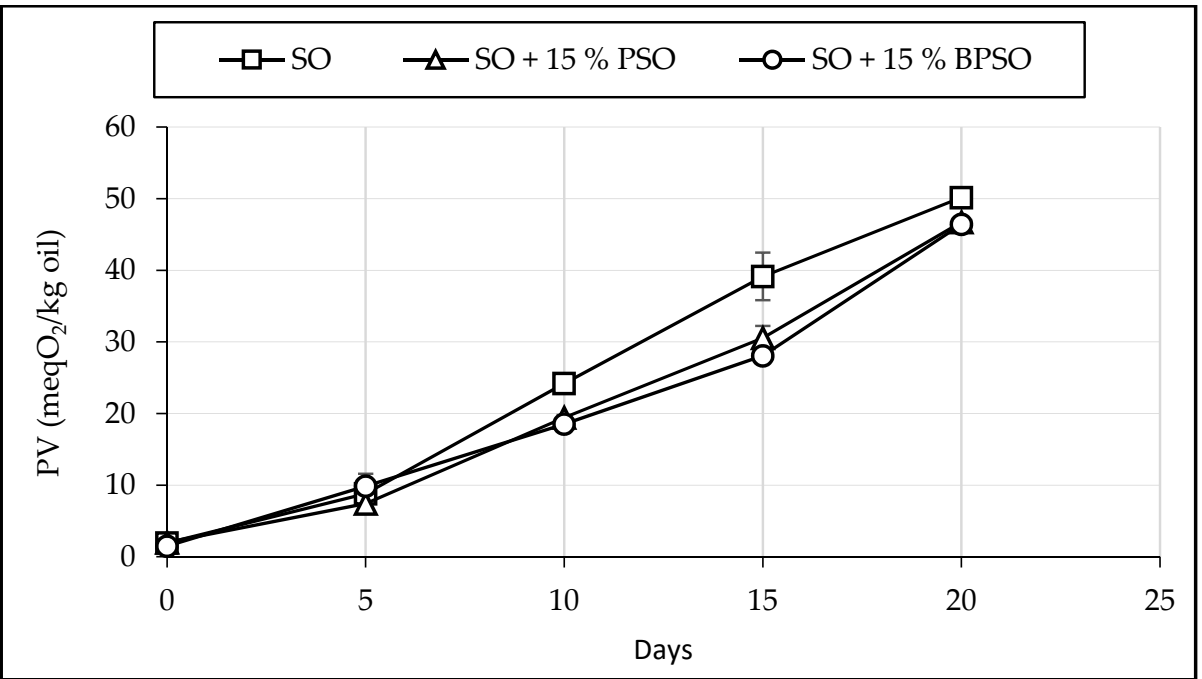

(a)

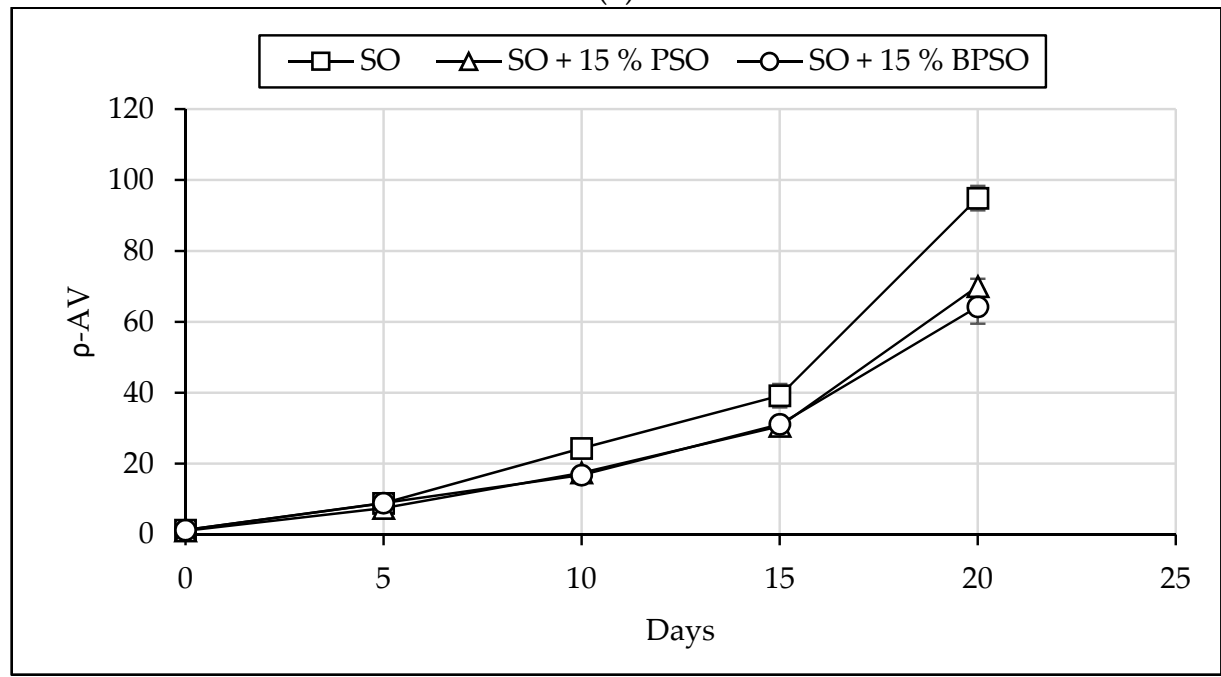

(b)

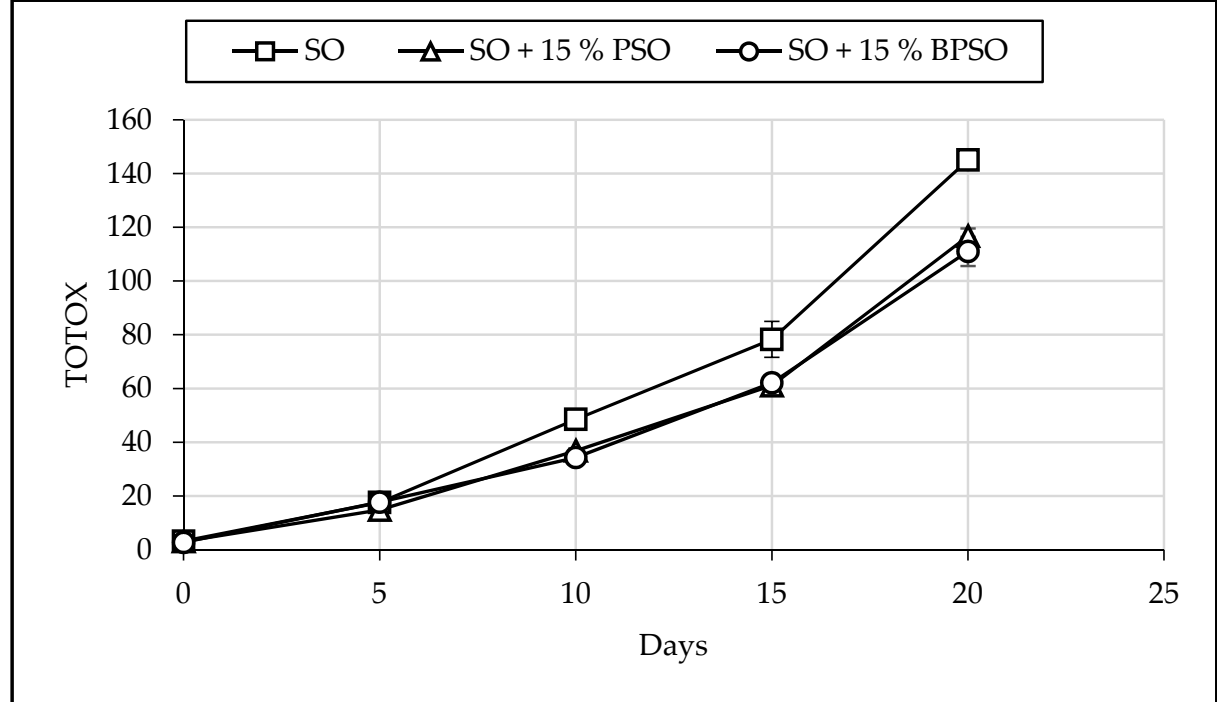

(c)

Figure 1. Changes in SO and oil blends $(85: 15 w / w)$ in (a) peroxide value (PV), (b) $\rho$-anisidine value ( $\rho$-AV), and (c) total oxidation value (TOTOX) during accelerated storage. Values given are the mean of three replicates. SO-sunflower oil, PSO_-pomegranate seed oil from unblanched seeds, BPSO_-pomegranate seed oil from blanched seeds. 


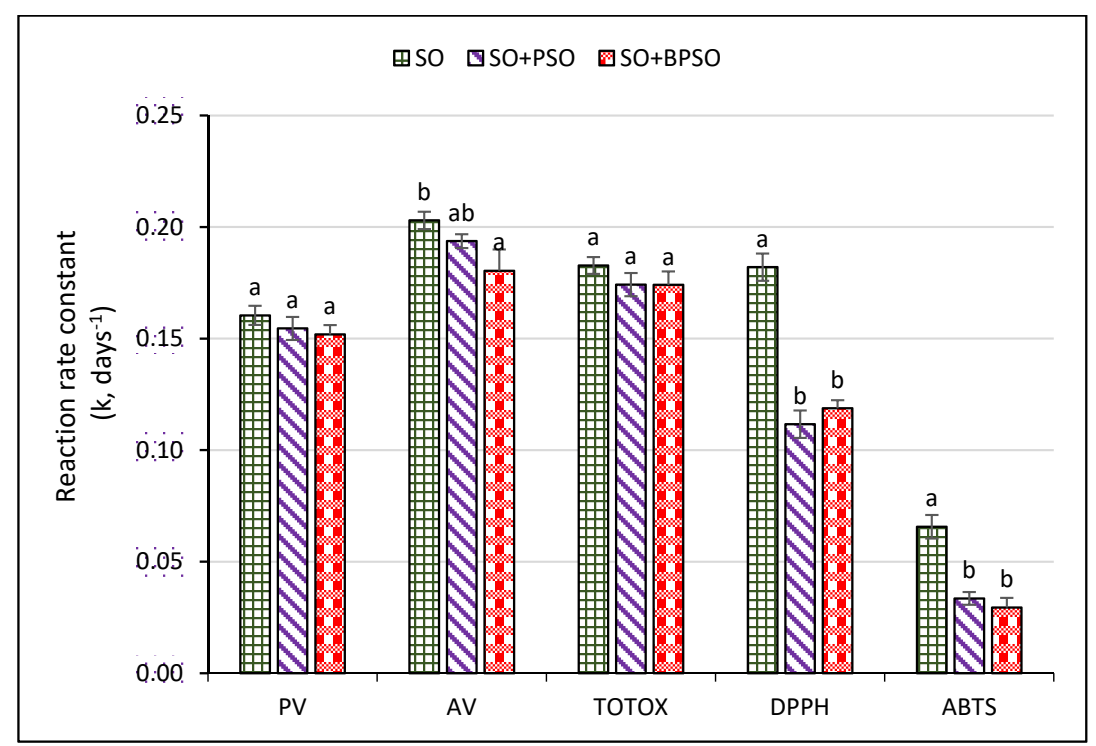

Figure 2. Reaction rate constants $\left(\mathrm{k}, \mathrm{day}^{-1}\right)$ of oxidation indices $(\mathrm{PV}, \mathrm{AV}$, and TOTOX) and radical scavenging capacity (DPPH and ABTS assays) in SO and oil blends $(85: 15 w / w)$ during accelerated storage following a first-order kinetic model. Within the same parameter, bars with different letters are significantly different $(p<0.05)$. SO-sunflower oil, PSO — pomegranate seed oil from unblanched seeds, BPSO—pomegranate seed oil from blanched seeds, TOTOX—total oxidation value, AV- $\rho$-Anisidine value, PV—peroxide value DPPH-2. 2-diphenyl-1-picryl hydrazyl, ABTS-2, 2'-azinobis (3-ethylbenzothiazoline-6-sulfonic acid).

\subsubsection{Para-Anisidine Value}

Although PV is a valuable biomarker in the early stages of lipid oxidation, it is not a sufficient indicator to estimate the extent of oil stability at elevated temperatures. Due to their instability, peroxides degrade into secondary oxidation products such as aldehydes, ketones, and alcohols, which are responsible for the off flavour in the oxidised edible oils [31]. Hydroperoxides are less heat stable than aldehydes; therefore, AV is considered a more reliable indicator of advanced oxidative rancidity in oils [29]. Figure $1 \mathrm{~b}$ presents the changes in the levels of $\mathrm{AV}$ in $\mathrm{SO}$ and oil blends during the 20 days of storage under accelerated conditions. The AV in all the oil samples increased steadily until day 15 , after which it drastically increased between 106 and 143\%. Day 15 also presented a slower rate in peroxides formation (Figure 1a), which is consistent with the phenomenon that the rate of peroxides accumulation slows down during the later stages of oxidation due to degradation into secondary products [32]. From day 0 to day 20, due to oxidation, AV of SO increased by 85 -fold, while the AV from SO:PSO and SO:BPSO blends increased by 63- and 47-fold, respectively. Indeed, the incorporation of PSO and BPSO to SO improved the oxidative stability of $\mathrm{SO}$ with respect to $\mathrm{AV}$. As shown in Figure 2, the reaction rate constant for $\mathrm{AV}$ in SO:BPSO $\left(0.180\right.$ units ${ }^{(\mathrm{n}-1)}$. day $\left.^{-1}\right)$ was significantly lower than that of SO $\left(0.203\right.$ units ${ }^{(n-1)}$. day $\left.{ }^{-1}\right)$, but not significantly $(p>0.05)$ different from that of SO:PSO blend $\left(0.194\right.$ units ${ }^{(n-1)} \cdot$ day $\left.^{-1}\right)$. Natural antioxidants including phenols, carotenoids, and tocopherols operate as either free radical scavengers, reducing agents, quenchers of the singlet oxygen, or complexers of prooxidants metals [33]. Two lines of reasoning suggested the reduced evolution of AV in SO:PSO and SO:BPSO blends during accelerated storage conditions. Firstly, the antioxidant compounds could have scavenged the generated radicals and slowed down the generation of secondary products of oxidation. Secondly, the increased proportion of SFAs (21-23\%) in blended oils could have decreased the susceptibility of the oils to oxidation.

\subsubsection{Total Oxidation Value}

The primary and secondary products of oxidation may be summed up to give the total oxidation value, which indicates both the oxidation history and further oxidation 
potential of the oils [31]. Therefore, the lower the oil TOTOX, the better the oxidative stability. Figure 1c depicts the changes in TOTOX of SO, SO:PSO, and SO:BPSO blends during accelerated storage. TOTOX of all oil samples increased during the accelerated storage period and presented a similar pattern to that of $\mathrm{AV}$, suggesting that the pattern of TOTOX increase was controlled more by the evolution of secondary oxidation products than primary oxidation products. Notably, after the $15^{\text {th }}$ day, sharp increases in the TOTOX corresponding to 85,91 , and 79\% for SO, SO:PSO, and SO:BPSO blends, respectively, were observed. The results indicate that SO and BSPO blend showed the lowest rate of increase in TOTOX, although the reaction rate constant was not significantly different from that of SO and SO:BPSO blend (Figure 2). Therefore, incorporation of PSO extracts from blanched seeds did not significantly $(p>0.05)$ slow down the rate of SO oxidation when compared with PSO extracts from unblanched seeds. After the incubation process, the TOTOX in SO, SO:PSO, and SO:BPSO were 145.05, 116.70, and 110.00, respectively. As highlighted previously, the introduction of 18:3 fatty acids from PSO and BPSO could have decreased its oxidative stability and increased the TOTOX, regardless of the higher antioxidant compounds. Seed oil oxidative stability is a function of several factors, which include fatty acid composition, antioxidant compounds, etc. Xu et al. [34] also emphasised the influence of fatty acid composition in seed oil oxidative stability when they compared the oxidative stability of camellia, palm, and peanut oil after frying potatoes.

\subsection{Changes in ABTS and DPPH Radical Scavenging Capacity during Accelerated Storage}

The ABTS assay measures the relative ability of antioxidants to scavenge the ABTS radical generated in the aqueous phase. The radical is soluble both in aqueous and organic solvents and therefore applicable to systems containing both hydrophilic and lipophilic components [35]. In this sense, ABTS radical scavenging capacity in the current study might have been influenced by the antioxidant compounds such as phenols, tocopherols, phytosterols, and carotenoids. Figure 3a shows that the ABTS radical scavenging capacity of SO decreased significantly from day 5 to day 10, whilst the ABTS radical scavenging capacity of SO:PSO and SO:BPSO decreased steadily throughout the accelerated storage period. The reaction rate constants support this observation for the depletion of ABTS radical scavenging capacity in SO, SO:PSO, and SO:BPSO, which were 0.066, 0.034, and 0.030 mmol Trolox ${ }^{(n-1)} \cdot$ day $^{-1}$, respectively (Figure 2 ). The results indicate that the ABTS radical scavenging capacity of SO decreased at double the rate of SO:PSO and SO:BPSO blends (Figure 3a). Comparing the SO:PSO and SO:BPSO blends, no significant variation $(p>0.05)$ in the rate of ABTS radical scavenging capacity depletion was observed. On the other hand, a strong positive correlation $(r=0.999)$ was observed between the reaction rate constants of TOTOX and ABTS indicating that the decrease in antioxidant compounds could have been the reason for the increased oil oxidation during the accelerated storage period (Table 3).

Table 3. Linear correlations for the reaction rate constants $\left(\mathrm{k}, \mathrm{day}^{-1}\right)$ of oxidation indices (PV, $\mathrm{AV}$, and TOTOX) and radical scavenging capacity (DPPH and ABTS assays) in SO and oil blends (85:15 $w / w)$ during accelerated storage following a first-order kinetic model.

\begin{tabular}{cccccc}
\hline & PV & AV & TOTOX & DPPH & ABTS \\
\hline PV & $\mathbf{1}$ & & & & \\
AV & 0.918 & $\mathbf{1}$ & & & \\
TOTOX & 0.972 & 0.801 & $\mathbf{1}$ & $\mathbf{1}$ & \\
DPPH & 0.921 & 0.692 & 0.987 & 0.979 & $\mathbf{1}$ \\
ABTS & 0.981 & 0.823 & $\mathbf{0 . 9 9 9}$ &
\end{tabular}

Values in bold are different from 0 with a significance level alpha $=0.05$. SO-sunflower oil, AV- $\rho$-Anisidine value, PV—-peroxide value TOTOX — total oxidation value, DPPH-2.2-diphenyl-1-picryl hydrazyl, ABTS-2.2' azinobis(3-ethylbenzothiazoline-6-sulfonic acid). 


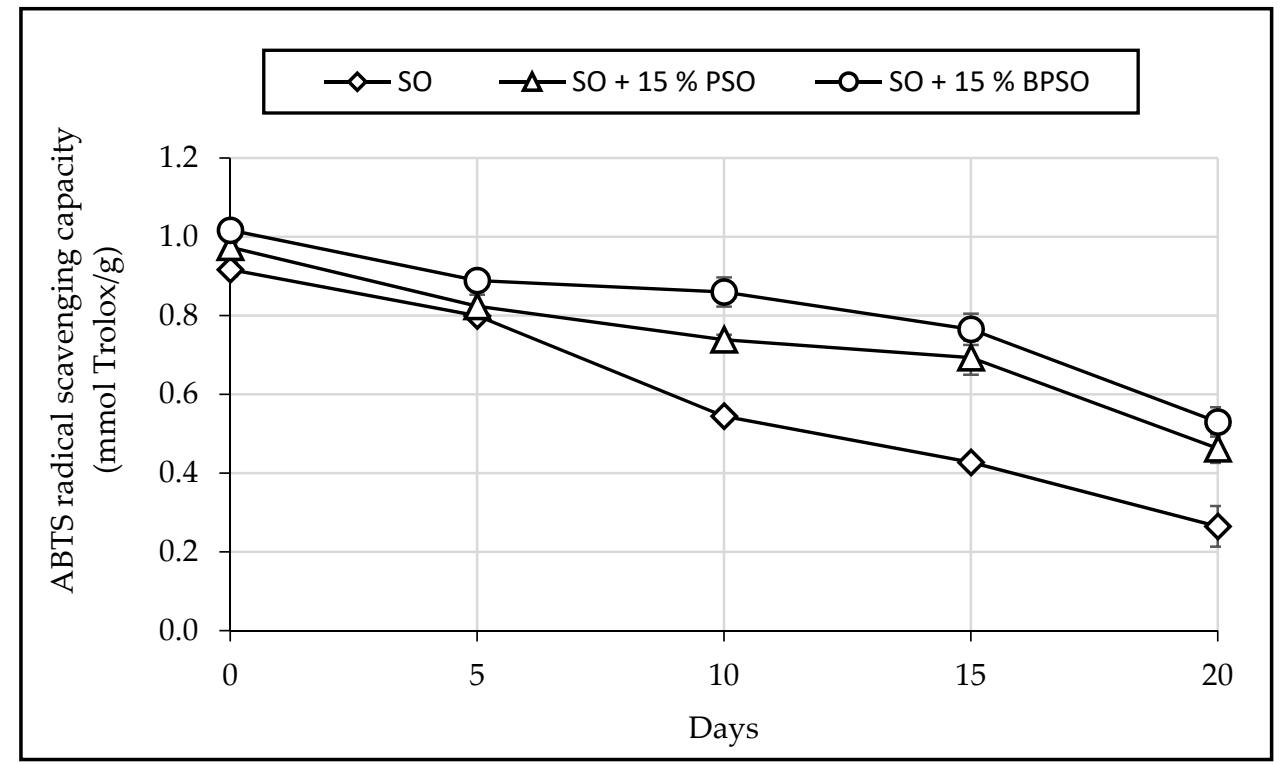

(a)

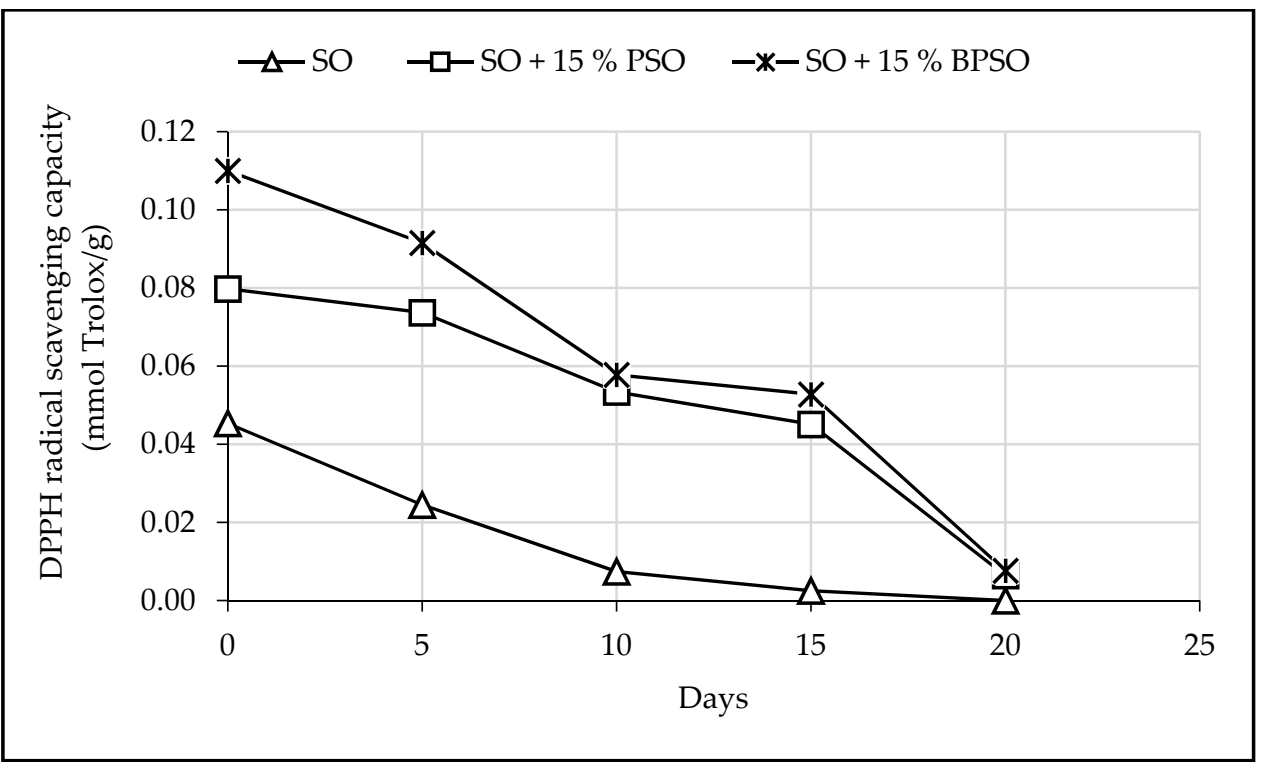

(b)

Figure 3. Changes in (a) ABTS and (b) DPPH radical scavenging capacity of SO and oil blends (85:15 w/w) during accelerated storage. Values given are the mean of three replicates. SO—sunflower oil, PSO—pomegranate seed oil from unblanched seeds, BPSO—pomegranate seed oil from blanched seeds, DPPH—2. 2-diphenyl-1-picryl hydrazyl, ABTS-2, 2'-azinobis(3-ethylbenzothiazoline-6-sulfonic acid).

The DPPH assay, which measures the ability of compounds to transfer labile $\mathrm{H}$-atoms to radicals, is the most common method for antioxidant activity evaluation. Changes in the DPPH radical scavenging capacity of $\mathrm{SO}$ and oil blends during the accelerated storage period are shown in Figure $3 \mathrm{~b}$. All oil samples demonstrated a DPPH radical time-dependent scavenging capacity. From Figure 3b, it is apparent that the DPPH radical scavenging capacity of SO decreased at a faster rate than that of SO:PSO and SO:BPSO. The finding concurs with results from previous studies [26]. The reaction rate constants for the depletion of DPPH radical scavenging capacity in SO, SO:PSO, and SO:BPSO were $0.182,0.111$, and $0.119 \mathrm{mmol}$ Trolox ${ }^{(\mathrm{n}-1)} \cdot$ day $^{-1}$, respectively. The results demonstrate that the impact of PSO and BSPO as additives to SO was strong, hence the steady decrease in 
DPPH radical scavenging capacity over time. This could be attributed to the significant improvement in TCC, TPC, and tocopherols content in the blended oils. From the $5^{\text {th }}$ to the $15^{\text {th }}$ day of accelerated storage, the DPPH radical scavenging capacity of SO was almost $50 \%$ lower than that of SO:PSO and SO:BPSO, suggesting that during this period, blended oils still had double the amount of antioxidant compounds when compared to the antioxidant compounds in SO. In a related study, Ramadan and Wahdan [1] blended corn oil with black cumin and coriander seed oil and observed a 12 to $36 \%$ inhibition of the DPPH radicals during the accelerated storage period. Improvement in the DPPH radical scavenging capacity was also reported in the study of Li et al. [36] from soybean oil blended with different types of specialty oils and subjected to accelerated storage conditions. Interestingly, at the end of the accelerated storage period, a significant decline in DPPH radical scavenging capacity of SO:PSO and SO:BPSO blends was observed. This could explain the significantly high levels of $\mathrm{PV}, \mathrm{AV}$, and TOTOX at the end of the incubation process (Figure 1).

\subsection{Volatile Oxidation Compounds Concentration at the End of Accelerated Storage Period}

A significant disparity was observed in the concentration of volatile oxidation compounds (VOCs) between the SO and oil blends (Table 4). In total, 22 common VOCs including alcohols, aldehydes, furans, ketones, and acids were identified in oils. These compounds have been acknowledged as the primary VOCs in previous studies depending on the stage of oil oxidation $[5,33,37]$. The relative content of VOCs in SO was significantly $(p<0.05)$ higher than that of SO:PSO and SO:BSPO blends. Moreover, certain VOCs including 2-heptanone, octanol, 1-octanol, 2.4-nonadienal, and 2-octenoic acid were only found in SO. As expected, no significant differences in the VOCs content between SO:PSO and SO:BSPO blends were observed. These results validate the finding that $\mathrm{AV}$ was significantly higher in SO but did not significantly vary in SO:PSO and SO:BPSO blends at the end of the accelerated storage period (Figure $1 b)$. In addition, a strong positive correlation $(r>0.90)$ between $\mathrm{AV}$ and the major aldehyde compounds, including n-hexanal and 2-heptanal at the end of the accelerated storage period, was observed (data not shown). Zhou et al. [38] also reported a strong correlation between $\mathrm{AV}$ and aldehyde compounds during accelerated oxidation of walnut oil. Therefore, aldehydes have been considered as good markers of seed oil oxidative degradation. In the present study, aldehydes were the principal VOCs in the headspace of the oxidised SO and oil blends, which was consistent with prior research [38]. Aldehydes and acids accounted for $68 \%$, whilst alcohols constituted $23 \%$ of the total VOCs. Furans and ketones were the least and represented less than $10 \%$ of the total VOCs. Similarly, Wang et al. [20] reported that aldehydes contributed close to $45 \%$ of the total VOCs in cold-pressed safflower seed oil. Overall, the mixture of these VOCs contributed to the rancid odour formed by the oxidation of $\mathrm{SO}$ and oil blends. Most of these secondary and tertiary oxidation products could have been derived from the degradation of linoleic acid, linolelaidic acid, and punicic acid, which were the most unsaturated fatty acids. According to $\mathrm{Mu}$ et al. [37], the possible mechanism for the formation of these VOCs, especially aldehydes, ketones, and alcohols is the rearrangement and scission of alkoxyl radicals. 
Table 4. Main volatile compounds identified in SO and oil blends $(85: 15 w / w)$ at the end of the accelerated storage period (20 days).

\begin{tabular}{|c|c|c|c|}
\hline \multirow[b]{2}{*}{ Compound } & \multicolumn{3}{|c|}{ Relative Content (\%) } \\
\hline & SO & SO:PSO & SO:BPSO \\
\hline Pentanal & $2.28 \pm 0.10^{b}$ & $3.74 \pm 0.51^{\mathrm{a}}$ & $4.18 \pm 0.28^{a}$ \\
\hline N-hexanal & $7.63 \pm 0.50^{c}$ & $3.16 \pm 0.09^{\mathrm{a}}$ & $1.46 \pm 0.85^{b}$ \\
\hline Trans-2-hexenal & $0.31 \pm 0.00^{\mathrm{a}}$ & $0.17 \pm 0.02^{b}$ & $0.22 \pm 0.03^{b}$ \\
\hline 2-Amylfuran & $0.98 \pm 0.02^{\mathrm{a}}$ & $0.14 \pm 0.01^{\mathrm{b}}$ & $0.12 \pm 0.01^{b}$ \\
\hline 1-Pentanol & $1.27 \pm 0.02^{\mathrm{a}}$ & $0.18 \pm 0.01^{b}$ & $0.18 \pm 0.01^{b}$ \\
\hline 2-Heptenal & $5.32 \pm 0.51^{\mathrm{a}}$ & $1.56 \pm 0.37^{b}$ & $1.73 \pm 0.07^{b}$ \\
\hline Acetic acid & $1.40 \pm 0.14^{\mathrm{a}}$ & $0.50 \pm 0.06^{b}$ & $0.55 \pm 0.03^{b}$ \\
\hline 1-Octen-3-ol & $1.78 \pm 0.14^{\mathrm{a}}$ & $0.21 \pm 0.03^{b}$ & $0.17 \pm 0.01^{b}$ \\
\hline Formic acid & $4.75 \pm 0.71^{\mathrm{a}}$ & $1.46 \pm 0.24^{b}$ & $1.59 \pm 0.08^{b}$ \\
\hline 2.4-Octadienal & $0.19 \pm 0.02^{\mathrm{a}}$ & ND & $0.05 \pm 0.00^{b}$ \\
\hline Butanoic acid & $0.05 \pm 0.01^{\mathrm{a}}$ & $0.09 \pm 0.01^{b}$ & $0.08 \pm 0.00^{a, b}$ \\
\hline 2-Decenal & $0.52 \pm 0.02^{\mathrm{a}}$ & $0.11 \pm 0.00^{b}$ & $0.09 \pm 0.01^{b}$ \\
\hline Pentanoic acid & $0.86 \pm 0.39^{a}$ & $2.20 \pm 0.17^{b}$ & $2.22 \pm 0.16^{b}$ \\
\hline Hexanoic acid & $7.68 \pm 0.44^{\mathrm{a}}$ & $2.39 \pm 0.11^{b}$ & $2.07 \pm 0.23^{b}$ \\
\hline Heptanoic acid & $0.23 \pm 0.00^{\mathrm{a}}$ & $0.06 \pm 0.01^{b}$ & $0.04 \pm 0.00^{b}$ \\
\hline Trans-2-tridecenal & ND & $0.05 \pm 0.00^{b}$ & $0.05 \pm 0.01^{b}$ \\
\hline 2-Heptanone & $7.63 \pm 0.50$ & ND & ND \\
\hline Octanol & $0.13 \pm 0.00$ & ND & ND \\
\hline 1-Octanol & $0.10 \pm 0.00$ & ND & ND \\
\hline 2.4-Nonadienal & $0.16 \pm 0.02$ & ND & ND \\
\hline 2-Octenoic acid & $0.38 \pm 0.04$ & ND & ND \\
\hline 2-Methyl-1-penten-3-ol & ND & $0.05 \pm 0.00$ & ND \\
\hline
\end{tabular}

Values (mean $\pm \mathrm{SD}, n=3$ ) in the same row with different superscript letters are significantly ( $p<0.05)$. ND—none detected, SO—sunflower oil, PSO—-pomegranate seed oil from unblanched seeds, BPSO—pomegranate seed oil from blanched seeds.

\section{Conclusions}

Blending SO with both PSO and BPSO significantly improved TPC, TCC, $\alpha$, and $\delta$-tocopherols content. With respect to fatty acids, incorporating PSO and BPSO in SO significantly increased palmitic acid, stearic acid, SFAs, MUFAs, MUFA:PUFAs index but did not significantly change the levels of PUFAs. This was valuable in improving the functionality of the SO. Higher levels of TCC and $\alpha$-tocopherols were shown by SO:BPSO blend, whilst TPC, $\delta$-tocopherol and fatty acid composition in the oil blends did not significantly differ. Blended oils exhibited better oxidative stability than $\mathrm{SO}$, which could improve the storability of SO. Nevertheless, oxidative stability of SO:PSO and SO:BPSO blends did not significantly vary. Additionally, blended oils showed a lower rate of DPPH and ABTS radical scavenging capacity depletion than $\mathrm{SO}$, although this did not significantly vary between the oil blends. The rate of TOTOX evolution was strongly and positively correlated $(r=0.999)$ to the rate of ABTS radical scavenging capacity depletion, indicating that antioxidant compounds play a major role in retarding oil oxidation. The concentration of VOCs was significantly higher in $\mathrm{SO}$ than blended oils. No significant difference in the content of VOCs was observed between SO:PSO and SO:BPSO blends. Based on the results, further studies would be important to establish the shelf life of the formulated blends under static conditions. Regarding pomegranate seed blanching as a way to enhance the oil functionality, studies on other blanching techniques, which may minimise leaching of water-soluble bioactive compounds should be considered for improved results. Based on our findings, the formulation of pomegranate seed oil blends $(85: 15(w / w))$ is crucial to the food industry, which is presently interested in nonconventional oils and functional foods to improve health and human nutrition. 
Author Contributions: T.K., O.A.F. and U.L.O., Conceptualisation, Writing-Review and editing; O.A.F. and U.L.O., Funding acquisition, Supervision, and Validation; T.K., Investigation, Methodology, Visualisation, Formal analysis, and Writing-Original draft preparation. All authors have read and agreed to the published version of the manuscript.

Funding: This research was funded by the National Research Foundation of South Africa; grant number 64813 and APC were partly funded by Stellenbosch University.

Institutional Review Board Statement: Not applicable.

Informed Consent Statement: Not applicable.

Data Availability Statement: Not applicable.

Acknowledgments: This study is based on the research supported wholly or in part by the National Research Foundation of South Africa (Grant Numbers: 64813). The opinions, findings and conclusions or recommendations expressed are those of the author(s) alone, and the NRF accepts no liability whatsoever in this regard.

Conflicts of Interest: The authors declare that they have no conflict of interest.

$\begin{array}{ll}\text { Abbreviations } \\ \text { ABTS } & \text { 2.2-azino-bis (3-ethylbenzothiazoline-6-sulfonic acid) } \\ \text { ANOVA } & \text { Analysis of Variance } \\ \text { AV } & \text { Anisidine value } \\ \text { BPSO } & \text { Pomegranate seed oil from blanched seed } \\ \text { COX } & \text { Calculated oxidation } \\ \text { DPPH } & \text { 2.2-diphenyl-1-picryl hydrazyl } \\ \text { FA } & \text { Fatty acid } \\ \text { FOX } & \text { Ferrous oxidation-xylenol orange } \\ \text { GC-MS } & \text { Gas chromatograph-mass spectroscopy } \\ \text { LDL } & \text { Low=density lipoprotein } \\ \text { MUFA } & \text { Monounsaturated fatty acid } \\ \text { ND } & \text { None detected } \\ \text { PS } & \text { Pomegranate seed } \\ \text { PSO } & \text { Pomegranate seed oil } \\ \text { PUFA } & \text { Polyunsaturated fatty acid } \\ \text { PV } & \text { Peroxide value } \\ \text { TCC } & \text { Total carotenoids content } \\ \text { SFA } & \text { Saturated fatty acid } \\ \text { SO } & \text { Sunflower oil } \\ \text { TOTOX } & \text { Total oxidation } \\ \text { TPC } & \text { Total phenolic content } \\ \text { UFA } & \text { Unsaturated fatty acid } \\ \text { VOC } & \text { Volatile oxidation compounds } \\ & \end{array}$

\section{References}

1. Ramadan, M.F.; Wahdan, K.M.M. Blending of corn oil with black cumin (Nigella sativa) and coriander (Coriandrum sativum) seed oil: Impact on functionality, stability, and radical scavenging activity. Food Chem. 2012, 132, 873-879. [CrossRef]

2. Mazaheri, Y.; Torbati, M.; Azadmard-Damirchi, S.; Savage, G.P. Effect of roasting and microwave pre-treatments of Nigella sativa L. seeds on lipase activity and the quality of the oil. Food Chem. 2019, 274, 480-486. [CrossRef]

3. Lourenco, S.C.; Moldão-Martins, M.; Alves, V.D. Antioxidants of natural plant origins: From sources to food industry applications. Molecules 2019, 24, 4132. [CrossRef]

4. Bordon, M.G.; Meriles, S.P.; Ribotta, P.D.; Martine, M.L. Enhancement of composition and oxidative stability of chia (Salvia hispanica L.) seed oil by blending with specialty oils. J. Food Sci. 2019, 84, 1035-1044. [CrossRef] [PubMed]

5. Kiralan, M.; Ulas, M.; Ozaydin, E.; Ozdem, E.; Ozkan, G.; Bayrak, A.; Ramadan, M.F. Blends of cold pressed black cumin oil and sunflower oil with improved stability: A study based on changes in the levels of volatiles, tocopherols and thymoquinone during accelerated oxidation conditions. J. Food Biochem. 2017, 41, 1-10. [CrossRef]

6. Aruna, P.; Manohar, B.; Singh, R.P. Processing of pomegranate seed waste and mass transfer studies of extraction of pomegranate seed oil. J. Food Process. Preserv. 2018, 42, 1-11. [CrossRef] 
7. Kaseke, T.; Opara, U.L.; Fawole, O.A. Novel seed pretreatment techniques: Effect on oil quality and antioxidant propertiesA review. J. Food Sci. Technol. 2021, 58, 1-14.

8. Kaseke, T.; Opara, U.L.; Fawole, O.A. Effect of blanching pomegranate seed on physicochemical attributes, bioactive compounds, and antioxidant activity of extracted oil. Molecules 2020, 20, 2554. [CrossRef] [PubMed]

9. Citeau, M.; Slabi, S.A.; Joffre, F.; Carré, P. Improved rapeseed oil extraction yield and quality via cold separation of ethanol miscella. Oilseeds Fats Crop. Lipids 2018, 25, 1-9. [CrossRef]

10. Sanchez-Machado, D.L.; Lopez-Cervantes, J.; Nunez-Gastelum, J.A.; Mora-Lopez, G.S.; Lopez-Henandez, J.; Paseiro-Losada, P. Effect of the refining process on moringa oleifera seed oil quality. Food Chem. 2015, 189, 53-57. [CrossRef]

11. Abbasi, H.; Rezaei, K.; Rashidi, L. Extraction of essential oils from the seeds of pomegranate using organic solvents and supercritical $\mathrm{CO}_{2}$. J. Am. Oil Chem. Soc. 2008, 85, 83-89. [CrossRef]

12. Ranjith, A.; Kumar, K.S.; Venugopalan, V.V.; Arumughan, C.; Sawhney, R.C.; Singh, V. Fatty acids, tocols, and carotenoids in pulp oil of three sea buckthorn species (Hippophae rhamnoides, H. salicifolia 2006, and H. tibetana) grown in the Indian Himalayas. J. Am. Oil Chem. Soc. 2006, 83, 359-364.

13. Fernandes, L.; Pereira, J.A.; Lopez-Cortes, I.; Salazar, D.M.; Ramalhosa, E.; Casal, S. Lipid composition of seed oil of different pomegranate (Punica granatum L.) cultivars from Spain. J. Food Compos. Anal. 2015, 39, 13-22. [CrossRef]

14. Mphahlele, R.R.; Fawole, O.A.; Makunga, N.P.; Linus Opara, U.L. Functional properties of pomegranate fruit parts: Influence of packaging systems and storage time. J. Food Meas. Charact. 2017, 11, 2233-2246. [CrossRef]

15. Fatemi, S.H.; Hammond, E.G. Analysis of oleate, linoleate and linolenate hydroperoxides in oxidized ester mixtures. Lipids 1980, 15, 379-385. [CrossRef]

16. Cruz, R.M.S.; Khmelinski, I.; Vieira, M.C. Methods in Food Analysis, 1st ed.; Taylor and Francis Group: New York, NY, USA, 2016.

17. AOCS. Official Methods and Recommended Practices of the American Oil Chemists' Society; Firestone, D., Ed.; AOCS Press: Champaign, IL, USA, 2003.

18. Siano, F.; Straccia, M.C.; Paolucci, M.; Fasulo, G.; Boscaino, F.; Volpe, M.G. Physico-chemical properties and fatty acid composition of pomegranate, cherry, and pumpkin seed oil. J. Sci. Food Agric. 2015, 96, 1730-1735. [CrossRef]

19. Uluata, S.; Ozdemir, N. Antioxidant activities and oxidative stabilities of some unconventional oilseeds. J. Am. Oil Chem. Soc. 2012, 89, 551-559. [CrossRef]

20. Wang, L.; Chen, Z.; Han, B.; Wu, W.; Zhao, Q.; Wei1, C.; Liu, W. Comprehensive analysis of volatile compounds in cold-pressed safflower seed oil from Xinjiang, China. Food Sci. Nutr. 2020, 8, 903-914. [CrossRef]

21. Latif, S.; Anwar, F. Physicochemical studies of hemp (Cannabis sativa) seed oil using enzyme-assisted cold-pressing. Eur. J. Lipid Sci. Technol. 2009, 111, 1042-1048. [CrossRef]

22. Bhatnagar, A.S.; Kumar, P.K.P.; Hemavathy, J.; Krishna, A.G.G. Fatty acid composition, oxidative stability, and radical scavenging activity of vegetable oil blends with coconut oil. J. Am. Oil Chem. Soc. 2009, 86, 991-999. [CrossRef]

23. Senyilmaz-Tiebe, D.; Pfaff, D.H.; Virtue, S.; Schwarz, K.V.; Fleming, T.; Altamura, S.; Muckenthaler, M.U.; Okun, J.G.; Vidal-Puig, G.; Nawroth, P.; et al. Dietary stearic acid regulates mitochondria in vivo in humans. Nat. Commun. 2018, 9, 1-10. [CrossRef] [PubMed]

24. Nadeem, M.; Abdullah, M.; Hussain, I. Improvement of the oxidative stability of butter oil by blending with moringa oleifera oil. J. Food Process. Preserv. 2014, 38, 1491-1500. [CrossRef]

25. Pieszka, M.; MigdaL, W.; Gdsior, R.; Rudzinska, M.; Bederska-Aojewska, D.; Pieszka, M.; Szczurek, P. Native oils from apple, blackcurrant, raspberry, and strawberry seeds as a source of polyenoic fatty acids, tocochromanols, and phytosterols: A health implication. J. Chem. 2015, 2015, 659541. [CrossRef]

26. Siraj, N.; Shabbir, M.A.; Khan, M.R.; Rehman, K.U. Preventing oxidation of canola and sunflower oils by addition of pomegranate seed oil. Acta Aliment. 2019, 48, 18-27. [CrossRef]

27. Cong, S.; Dong, W.; Zhao, J.; Hu, R.; Long, Y.; Chi, X. Characterization of the lipid oxidation process of robusta green coffee beans and shelf-life prediction during accelerated storage. Molecules 2020, 25, 1157. [CrossRef] [PubMed]

28. Choe, E.; Min, D.B. Mechanisms of antioxidants in the oxidation of foods. Compr. Rev. Food Sci. Food Saf. 2009, 8, 345-358. [CrossRef]

29. Choe, E.; Min, D.B. Mechanisms and factors for edible oil oxidation. Compr. Rev. Food Sci. Food Saf. 2006, 5, 169-186. [CrossRef]

30. Codex Alimentarius. Standard for Named Vegetable Oils- Codex Stan 210-1999; Codex Alimentarius: Rome, Italy. Available online: http://www.fao.org/fao-who-codexalimentarius/codex-texts/list-standards (accessed on 7 September 2020).

31. Koohikamali, S.; Alam, M.S. Improvement in nutritional quality and thermal stability of palm olein blended with macadamia oil for deep-fat frying application. J. Food Sci. Technol. 2019, 56, 5063-5073. [CrossRef]

32. Ali, M.; Imran, M.; Nadeem, M.; Khan, M.K.; Sohaib, M.; Suleria, H.A.R.; Bashir, R. Oxidative stability and sensoric acceptability of functional fish meat product supplemented with plant based polyphenolic optimal extracts. Lipids Health Dis. 2019, 18, 1-16. [CrossRef]

33. Ramadan, M.F.; Sitohy, M.Z.; Moersel, J. Solvent and enzyme-aided aqueous extraction of goldenberry (Physalis peruviana L.) pomace oil: Impact of processing on composition and quality of oil and meal. Eur. Food Res. Technol. 2008, 226, 1445-1458. [CrossRef]

34. Xu, T.; Li, J.; Fan, J.; Zheng, T.; Deng, Z. Comparison of oxidative stability among edible oils under continuous frying conditions. Int. J. Food Prop. 2015, 18, 1478-1490. [CrossRef] 
35. Karadag, A.; Ozcelik, B.; Saner, S. Review of methods to determine antioxidant capacities. Food Anal. Methods 2009, 2, 41-60. [CrossRef]

36. Li, Y.; Ma, W.; Qi, B.; Rokayya, S.; Li, D.; Wang, J.; Feng, H.; Sui, X.; Jiang, L. Blending of soybean oil with selected vegetable oils: Impact on oxidative stability and radical scavenging activity. Asian Pac. J. Cancer Prev. 2014, 15, 2583-2589. [CrossRef]

37. Mu, H.; Gao, H.; Chen, H.; Fang, X.; Zhou, Y.; Wu, W.; Han, Q. Study on the volatile oxidation compounds and quantitative prediction of oxidation parameters in walnut (Carya cathayensis Sarg.) oil. Eur. J. Lipid Sci. Technol. 2019, 121, 1800521. [CrossRef]

38. Zhou, Y.; Fan, W.; Chu, F.; Wang, C.; Pei, D. Identification of volatile oxidation compounds as potential markers of walnut oil quality. J. Food Sci. 2018, 83, 2745-2752. [CrossRef] 